\title{
Overdentures Supported by Mini or Conventional Implants-effect on Patient Satisfaction and Bone Resorption Rates. A Randomized Clinical Trial
}

\author{
Osama Ahmed Gaballa ${ }^{1 *}$, Hamdy Abo El Fotouh Hamed ${ }^{2}$, Ahmed Emad Fayyad ${ }^{2}$, Mohamed Marwan Rahhal ${ }^{1}$ \\ ${ }^{1}$ Department of Prosthodontics, Faculty of Oral and Dental Medicine, Fayoum University, Faiyum, Egypt; ${ }^{2}$ Department of \\ Prosthodontics, Faculty of Oral and Dental Medicine, Cairo University, Giza, Egypt
}

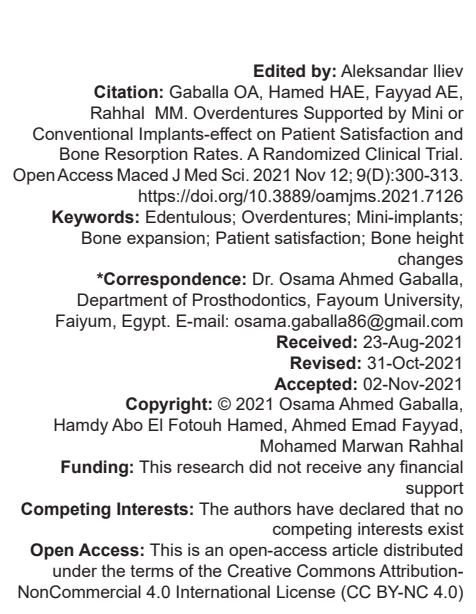

Abstract

AIM: The aim of the study was to assess the difference between patient satisfaction and bone height changes of mini-implant supported overdentures in comparison with conventional implant after bone expansion technique.

METHODS: This randomized clinical trial contains 36 edentulous participants with thin mandibular ridges randomly divided to receive 2 mini-implants, or 2 conventional implants after ridge splitting, both treatments were done in the inter-forminal area of the anterior mandible. Then, the patients received mandibular overdentures with ball and socket attachments. At base line, after 6 and 12 months of loading the implants, patients' satisfaction was evaluated using visual analog scale, in addition to bone height changes using Soredex DIGORA Optime Classic software.

RESULTS: There was statistically significant difference in the overall satisfaction between the mini-implants and the conventional implants group; the amount of bone height changes in the mini-implant group was statistically significant less than the conventional implant group at base line, 6 and 12 months.

CONCLUSION: Treatment with two mini-implants provides high level of satisfaction and less bone height changes in a follow-up period of 12 months in comparison to conventional implants after ridge expansion.

\section{Introduction}

Ridge resorption causes lack of retention and compromises the function of complete dentures. Implants offer us a way to give our patients a solution for these chronic problems.

However, root-form implants have limitations related to cost, anatomical considerations, health of the patient and the dentist's technical ability. Implant-supported overdenture could be used as alternative to achieve more retention and give better acceptance for edentulous patients. The presence of the implants underneath the mandibular dentures offer better retention, improved appearance, higher chewing efficiency, and less bone resorption and muscle atrophy than the conventional dentures [1].

Numerous studies have assessed patient satisfaction with implant-retained mandibular overdentures compared to their satisfaction levels with prior complete dentures (i.e., without implants), finding higher satisfaction ratings with the implant-retained overdentures - one study measured this as 36\% higher.
Many patients just cannot afford a multiple root-form implant-supported fixed lower denture [2].

Mini-implants are no longer transitional but offer a solution to the problems of denture instability, lack of retention and denture-related discomfort, and therefore also a solution for the unsatisfied denture patient. Mini-implants are minimally invasive compared to wider-diameter implants and typically have a shorter healing period. The surgical procedure is less complex, quicker and less invasive, and the insertion of the implants is simpler [3].

They can be immediately loaded and have also been found to be cost-effective [4]. Placement of Mini Dental Implants can be performed with or without a surgical flap. As with standard-diameter implants, patients receiving mini-implants for overdenture treatment have reported higher satisfaction rates, and high success rates have been obtained [5].

The standard protocol for management of thin ridge is bone augmentation. Several bone augmentation techniques can convert the thin ridge to a wider one However, bone augmentation requires more time and more complicated procedure to correct 
the thin alveolar ridge. Single-stage immediate implant placement and lateral ridge augmentation could be valid if crest-splitting bone expansion technique executed in thin crests which in turns prevent neurosensory deficiencies. Ridge expansion with implant supported over denture is known to correct the thin alveolar ridge in short time.

Ridge expansion seems to be a simple and effective procedure that can correct the thin ridge immediately to allow room for wider implants which can withstand forces and to prevent alveolar bone loss as much as possible [6]. Ridge expansion gained some popularity due to easiness compared to any other procedure that can gain bone. However, this treatment modality needs to be evaluated as compared to Mini Dental Implants (MDIs) over denture in thin mandibular ridge [7].

\section{Methods}

\section{Trial design}

The study was designed to be a parallel randomized comparator trial. The patients were randomized into either one of the following groups:

- (Group I): Patients treated with mandibular overdenture supported by mini dental implant.

- (Group II): Patients treated with mandibular overdenture supported by conventional implant diameter after bone expansion.

Approval of study protocol was done by centre of evidence-based dentistry (CEBD-CU committee), Prosthodontic Department Board and Ethics Committee of Dentistry, Cairo University.

\section{Registration \\ NCT03326453 Clinicaltrial.gov}

\section{Participants}

\section{Sample size calculation}

To detect the sample size estimation for "Effect of Mini-Implants Supported Over Dentures versus Conventional Implant after Bone Expansion in Thin Mandibular Ridge on Patient Satisfaction"; data from a previous study [8] was used to estimate that the total sample size of 36 ( $n=18$ for each group) would be sufficient to achieve a power of $80 \%$ and yield a statistical significance, and a 0.05 significance level. Sample size calculation was done using IBM ${ }^{\mathrm{TM}}$ SPSS $^{\mathrm{TM}}$ SamplePower ${ }^{\text {TM }}$ Version 3.0.1

\section{Selection criteria}

36 completely edentulous patients, in an age range of 50-70 years with mean 60 years were selected from the outpatient clinic of the prosthodontic department, Faculty of Dentistry, Cairo University.

Patients have met the following criteria:

- $\quad$ Completely edentulous patients with age range from 40 to 70 years

- $\quad$ Angle's Class I skeletal relationship

- $\quad$ Normal facial symmetry with no signs and symptoms of temporomandibular disorders.

- $\quad$ Cooperative patients

- $\quad$ Adequate inter-arch space not less than $12 \mathrm{~mm}$

- Completely edentulous maxillary and mandibular arches where the mandibular arch could be restored with an implant supported overdenture.

- Edentulous ridge covered by healthy firm mucoperiosteum, without abnormal morphology.

- A period of at least 6 months from the date of last extraction.

- $\quad$ Normal size tongue.

- Oral cavity should be Free from any oral pathological lesions such as cysts, remaining root, or residual infection.

- $\quad$ Not heavy smokers (> 10 cigarettes/day).

- $\quad$ Free from any systemic diseases that might affect the bone quality or post-operative healing.

\section{Patient examination}

First of all, initial evaluation was done to include only the patients who met the study selection criteria. This evaluation consisted of; medical history questionnaire, a clinical examination and radiographic examination.

\section{dental history}

\section{Extra-oral examination}

Temporomandibular joints and muscles of mastication, facial symmetry, and activity of the lips were included in extra-oral examination.

\section{Intra-oral examination}

The proposed implant site was evaluated intra-orally through:

Visual assessment: Oral structures examined for any signs of inflammation or ulceration as in the edentulous ridge, tongue, cheeks, lips, and 
palate had been treated before prosthetic and surgical procedures.

Digital assessment: Additional examination of the residual ridge was done using digital examination (finger pressure) to verify mucoperiosteal firmness and to distinguish flabby tissues, sharp bony ridges, excessive undercuts, and ridge discrepancies.

Laboratory investigations:

- Complete blood count (CBC).

- $\quad$ Blood clotting tests (INR)

- $\quad$ Glycosylated hemoglobin test (HbA1C)

\section{Pre-operative photos}

Extra-oral and Intra-oral photographs.

\section{Mounted diagnostic casts}

First, primary impression was taken using alginate in a suitable perforated stock tray, tentative jaw relation was recorded, then maxillary and mandibular impressions were poured to obtain primary cast on which occlusion blocks were fabricated, then diagnostic casts were mounted on an articulator.

\section{Radiographic investigations}

Panoramic radiographs were essential to check the absence of impacted teeth, remaining roots and pathological lesions, also to verify tentative measurements of the available bone height at estimated the implant site.

\section{Informed consent}

Oral and written information about the nature of the research work, the dental implant, surgical and prosthodontic procedures were informed to the selected patients. For each patient, informed consent was obtained. Only patients who were motivated and showed co-operation participated in the study. The ethical clearance for the study was obtained from the Ethics Committee of Cairo University (Reference no. 17-12-13)

\section{Interventions and Study Procedures}

\section{Complete denture construction}

For all patients a conventional complete denture (CD) was constructed until dividing the patients into two sub-groups following the traditional steps.

\section{Construction of the radiographic stent}

Duplication of the mandibular denture was performed with silicone ${ }^{1}$ material into acrylic resin ${ }^{2}$ (mixed with Barium sulfate as radiopaque material). After polymerization, the stent was removed from the duplicated mold and excess acrylic was removed. This duplicate was used in two phases, first as a radiographic template and then as a surgical stent. In the fitting surface of the template a through and through cavities were drilled corresponding to the premolars and anterior teeth in both right and the left sides for placement of two implants. The radiographic guide was worn by the patient during a CBCT scan, where it was stabilized in its position by the upper denture (Figure 1).

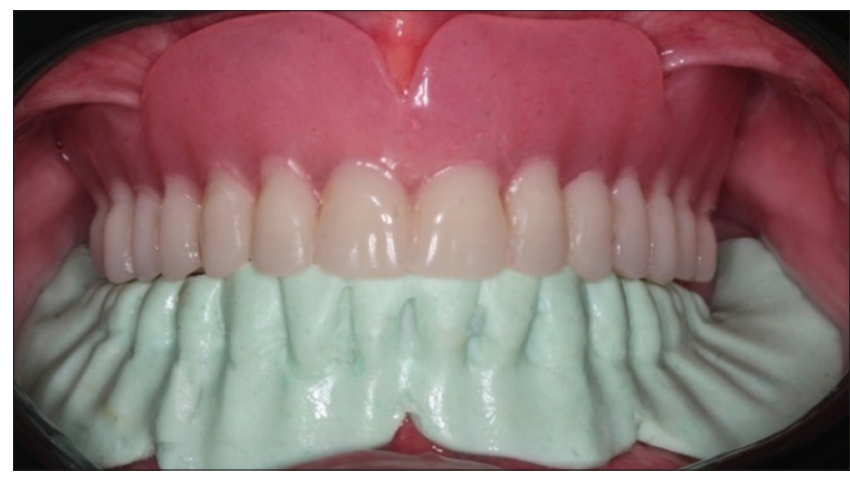

Figure 1: The radiographic guide for $C B C T$ scan

\section{Measurements on CBCT scan}

The DICOM file of the CBCT was uploaded on OnDemand3D $®$ software. To confirm the proposed position of the implant, the distance from the canine/lateral region to the mental foramen was measured as it should be $\geq 5 \mathrm{~mm}$ mesial to the mental foramina. Then an axial section of the canine/lateral region was cut, to measure the width and the height of the bone at the proposed implant site.

\section{Patients Grouping (Randomization Process)}

\section{Allocation}

\section{Sequence generation}

Allocation was done using computer generated website (www.random.org) for randomization thus eligible patients were allocated by ratio $1: 1$ as treatment (intervention) and control (comparator) groups.

1 Zhermac PUTTY C-silicone impression material, 45021 Badia Polesine (Rovigo) - Italy

2 Peka tray Acrostone, England. 


\section{Allocation concealment mechanism}

Opaque sealed envelopes were used for allocation concealment. Each envelope contained a code number that was given to each participant.

\section{Implementation}

Eligible patients receive a sealed envelope, inside each a code to assign each participant to treatment or control group.

\section{Blinding (masking)}

This trial was double blinded as the patients and the statistician were blinded. The principal investigator could not be blinded as the implant placement technique for both groups was different, and both techniques were carried out by the principal investigator O.G and supervised by A.F. During assessment of secondary outcome (bone height change) the $\mathrm{X}$-ray revealed the difference in the shape of both types of implants therefore assessor could not be blinded.

\section{Pre-surgical preparation}

The patient was instructed to rinse with $0.12 \%$ Chlorhexidine mouth wash ${ }^{3}$ as antimicrobial prophylaxis 3 times per day 2 days before surgery. Furthermore, the patient was instructed to take $1 \mathrm{~g}$ antibiotic $1 \mathrm{~h}$ before surgery ${ }^{4}$. The surgical stent was disinfected by a disinfectant agent ${ }^{5}$ then checked intra-orally for proper extension and stability.

\section{Surgical Procedure}

\section{Flap incision and reflection}

After administrating adequate local anesthesia ${ }^{6}$ a crestal incision was made by Bard Parker blade no. 15 , the incision extending bilaterally from the right to left mental foramens followed by two vertical releasing incisions. A full thickness mucoperiosteal flap was reflected by sharp mucoperiosteal elevator. A bone file was then used to correct any crestal bone irregularity.

\section{Plateauing}

Using bone trimmer ${ }^{7}$, the narrow edge of the alveolar crest was flattened and smoothed out. To

\footnotetext{
3 Chlorhexidine,Kahira Pharm.and chem.Ind.Co.Egypt

4 Augmentin, GalaksoSmithKline, Germany.

5 Cidex Activated Dialdehyde Solution.J. and J.Medical

6 Ubistesin forte, 3M ESPE AG_Germany

7 Bone trimmer, Ridge wider kit, Neo Biotech Ver.0
}

create a bone plateau; the bone trimmer was used with a speed $1200 \mathrm{rpm}$.

\section{Positioning (point of entry)}

After creating a smooth bone plateau, the surgical stent was inserted in the patient's mouth. The locator drill (Lindman guiding drill) $)^{8}$ was then used to make a point of entry through the surgical guide to mark the site of implant insertion. Afterward, manual confirmation of the proposed implant site was performed using probe; the distance from the point of entry was measured in relation to the midline.

\section{Intervention Group (Mini Dental Implant)}

\section{Osteotomy procedures}

After confirmation of the site of implant, the drilling was done in a sequential manner into a depth of $10 \mathrm{~mm}$ guided by the laser mark on the drills. The first drill ${ }^{9}$ with diameter $1.75 \mathrm{~mm}$ was used in the right and left implant sites. The following drill with diameter ${ }^{10} 2.35 \mathrm{~mm}$ was then used to create the final osteotomies. During the drilling procedures, parallel pins were repositioned after each drill to ensure the parallelism of the osteotomy sites.

\section{Implant placement}

The cap was held to start implant placement. The mini-implant ${ }^{11}$ ( $2.5 \mathrm{~mm}$ diameter and $10 \mathrm{~mm}$ length) was inserted with the cap by manual force. Once $5 \mathrm{~N}$.cm of torque was reached, the connection between the cap and fixture deformed. After that the disengaged cap was removed. Then implant placement was continued using mini-implant driver tool. During implant placement of the first implant the parallel pin was kept in the other site to confirm proper alignment of the implant. The contra-lateral mini-implant was placed in the same sequence (Figure 2). Finally, the flap was sutured in a continuous manner with lock technique. The suture was perfumed tension free using surgical silk or polypropylene 410 suture $^{12}$.

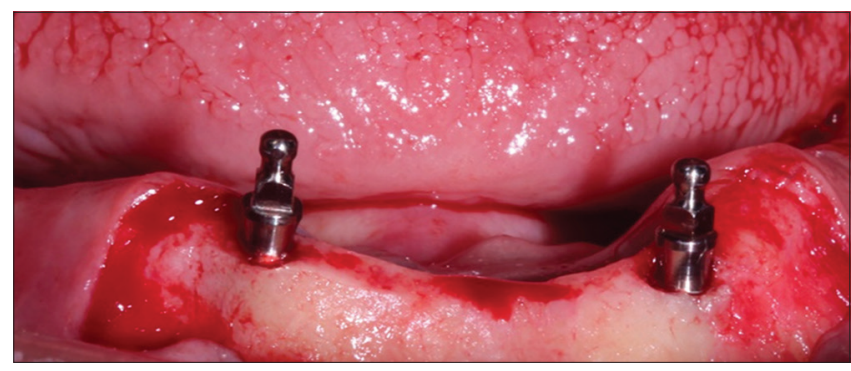

Figure 2: The two mini-implants in place

8 Dentium Korea SuperLine \& Implantium surgical kit

9 Dentium. Korea, Slim Line surgical kit

10 Dentium. Korea Slim Line surgical kit

11 Dentium, SlimLine, Korea.

12 4/0 silk black braided sutures, Assut 


\section{Comparator group (conventional implant diameter after bone expansion)}

\section{Ridge splitting procedures}

After plateauing as previously mentioned, the ridge wider kit of NeoBiotech ${ }^{13}$ was used to perform ridge splitting (Figure 3). First, the non-saw disc was used on the ridge side to side from the two points of entry which were created. The non-saw disc was used to confirm the flattening of the ridge and making a trough along the crest to maximize the safety in the following step by preventing the possibility of slipping of the saw disc that will be used afterwards. The saw type discs were used in sequential manner (7-, 10-, and $13-\mathrm{mm}$ diameter) side to side guided with the trough connecting the two points of entry. A vertical split cut was then performed distal to each point of entry in the labial cortical plate. Finally, the ridge splitting procedure resulted in one crestal cut passing from canine-tocanine region and two vertical cuts at its end.

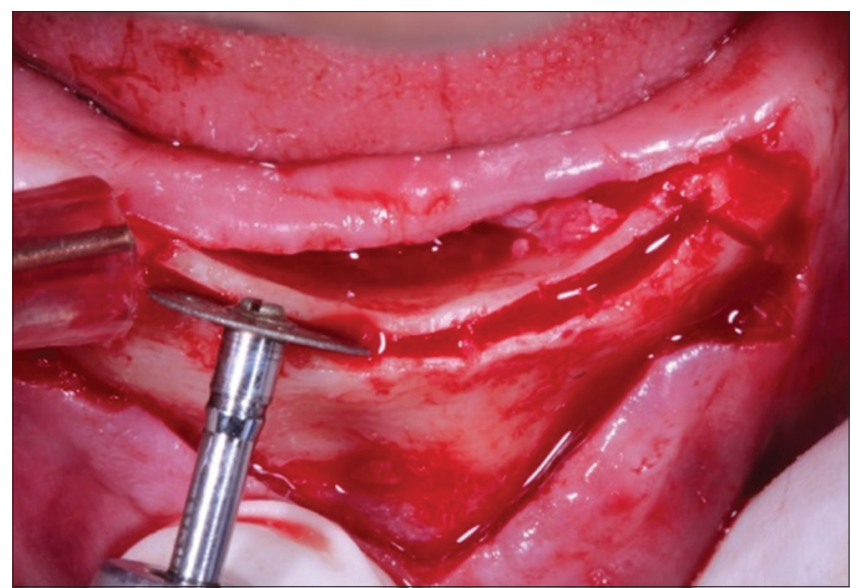

Figure 3: Ridge splitting with disc $13 \mathrm{~mm}$

\section{Ridge expansion}

The locator drill (Lindman guiding drill) was reinserted again but in full depth of $10 \mathrm{~mm}$ in the point of entry marked before ridge splitting. At the same time, the parallel pin was inserted in the contra-lateral implant site to confirm the proper alignment. After drilling the two parallel pins were inserted, additionally peri-apical radiograph was taken to ensure parallelism. The engine-driven expanders were then used in sequence in the site of implant insertion. The first expander of $3 \mathrm{~mm}$ diameter was inserted with low and persistent speed of 25 35rpm. During insertion of the expander, the labial bone was supported with finger and the bone was carefully observed if any signs of cracking occurred. The first expander was sustained in place for a while after reaching the full length to allow the bone expansion, maintain the expansion performed and prevent bone relapse. After the bone was fully expanded, the first expander was removed and the

\section{Ridge wider, NeoBiotech, Korea}

second one with diameter $3.5 \mathrm{~mm}$ was inserted with the same method then the procedures were repeated in the contralateral site (Figure 4).

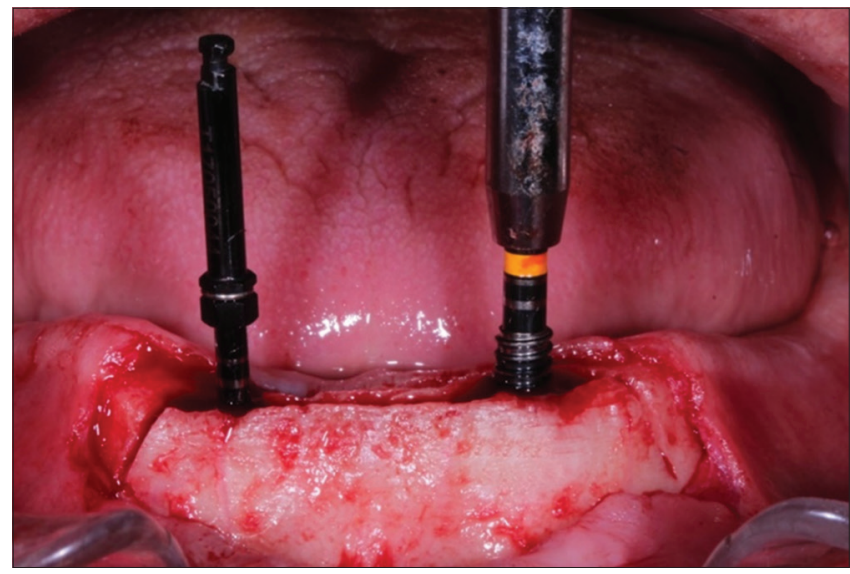

Figure 4: Insertion of first expander of $3 \mathrm{~mm}$ diameter in right side while second engine driven expander $3.5 \mathrm{~mm}$ in the left side

\section{Implant placement}

After sufficient expansion, conventional implants were placed following the standard procedures. Implants (Dentium, Super Line, Korea) of $3.6 \mathrm{~mm}$ diameter and $10 \mathrm{~mm}$ length were selected. The implants were placed using ratchet with $35 \mathrm{~N} . \mathrm{cm}$ torque with sufficient primary stability immediately after removal of the expanders. Afterward, covering screws were placed then tension free suture was performed ${ }^{14}$ (two surgical-step technique) (Figure 5).

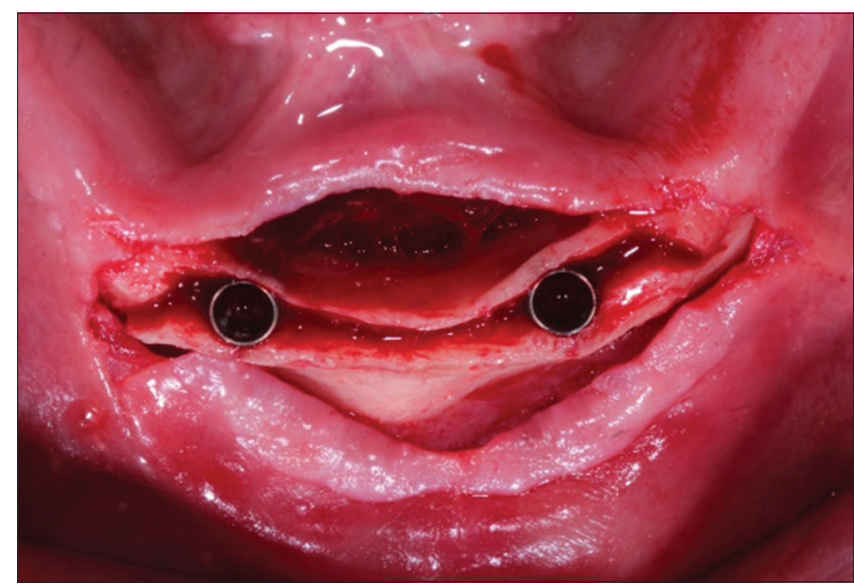

Figure 5: Two implants in place, occlusal view

\section{Post-operative instructions}

Patients of both groups were given the following instruction:

- $\quad$ Undertake the usual oral hygiene measures in combination with chlorhexidine mouth wash 3-4 times daily for chemical plaque control.

Patients were recalled after 1 week for suture

14 4/0 silk black braided non-absorbable-sutures, Assut 
removal and were strictly instructed regarding the proper oral hygiene measures.

\section{Denture Relining}

The patients were recalled after 2 weeks for denture relining. For the intervention group, the denture was relieved opposing to the ball stud of the miniimplants. Direct soft relining was performed in patient's mouth using soft relining material ${ }^{15}$ and the denture was delivered to the patient

\section{Second Stage Surgery in Comparator Group}

After 3 months, the patients of the comparator group (conventional implant after expansion group) were recalled for second stage surgery. An exposure was made in canine/lateral region opposing the implants. The cover screws were then removed using screw driver.

The tissue thickness was measured from the top of the prosthetic platform to the crest of the gingiva at its highest point, to choose the proper ball attachment size. The abutment collar height was chosen to be $1 \mathrm{~mm}$ higher than the tissue height, so that no tissue was above the shoulder of the collar.

The proper ball abutment ${ }^{16}$ was then inserted onto each implant using ball driver. After that, a radiograph was taken along to ensure the abutments were seated completely on the implants.

\section{Chair-side Pick-up Using the Existing Denture for Both Groups}

For both groups, chair-side pickup procedures were done to retain the over-denture. First, the areas in the denture opposing the ball abutments were marked. Recesses were prepared in the denture to accommodate space for the housings. A space between the housings and the denture was created to ensure that there was no contact between the denture and the housings. Any undercuts were blocked out beneath the housing and soft tissue to prevent the acrylic resin from locking the denture onto the abutment. The denture

15 Acrostone, England

16 Dentium korea was then seated to make sure that the denture was not touching the housings

Permanent self-curing acrylic resin ${ }^{17}$ was added on the ball attachment housings for bonding to the denture. Another small amount of material was added into the recessed area of the denture and around the titanium housings.

Afterward, the mandibular denture was inserted and seated guided by the maxillary denture under biting force. The mandibular denture was maintained in a passive position without compressing the soft tissue while the relining material sets. At the end, the occlusion and the tissue side of the denture were adjusted according to the new position. Polishing was done after adjustments (Figure 6).

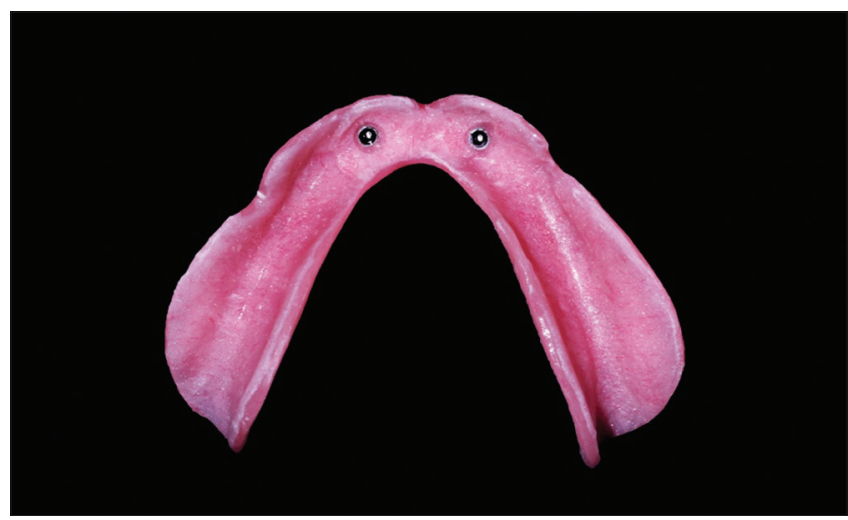

Figure 6: Final mandibular denture after pick up

\section{Outcomes}

\section{Primary outcome}

Patient Satisfaction through patient questionnaire and the Visual Analogue Scale (VAS).

Patient questionnaires (Figure 7) were used to record the patient's subjective experiences with the implant-supported mandibular overdentures. Subjects were asked to grade their overdentures on a 0 - to $100-\mathrm{mm}$ visual analog scale for five factors: The general degree of satisfaction, ease of adaptation to the new prosthesis with no pain or ulceration, chewing ability in comparison with previous dentures, esthetics, and speech. The patients indicated a position on the line corresponding to their estimated agreement of perception which can be measured to the nearest millimeter using a ruler. The higher the score, the more satisfied the subjects were. The same procedure was repeated for all questions of VAS at the following periods: At baseline (at time of denture insertion), 6 months, and finally at 12 months.

17 Acrostone, Dental Factory -Industrial Zone, Salam City,A.R.E 


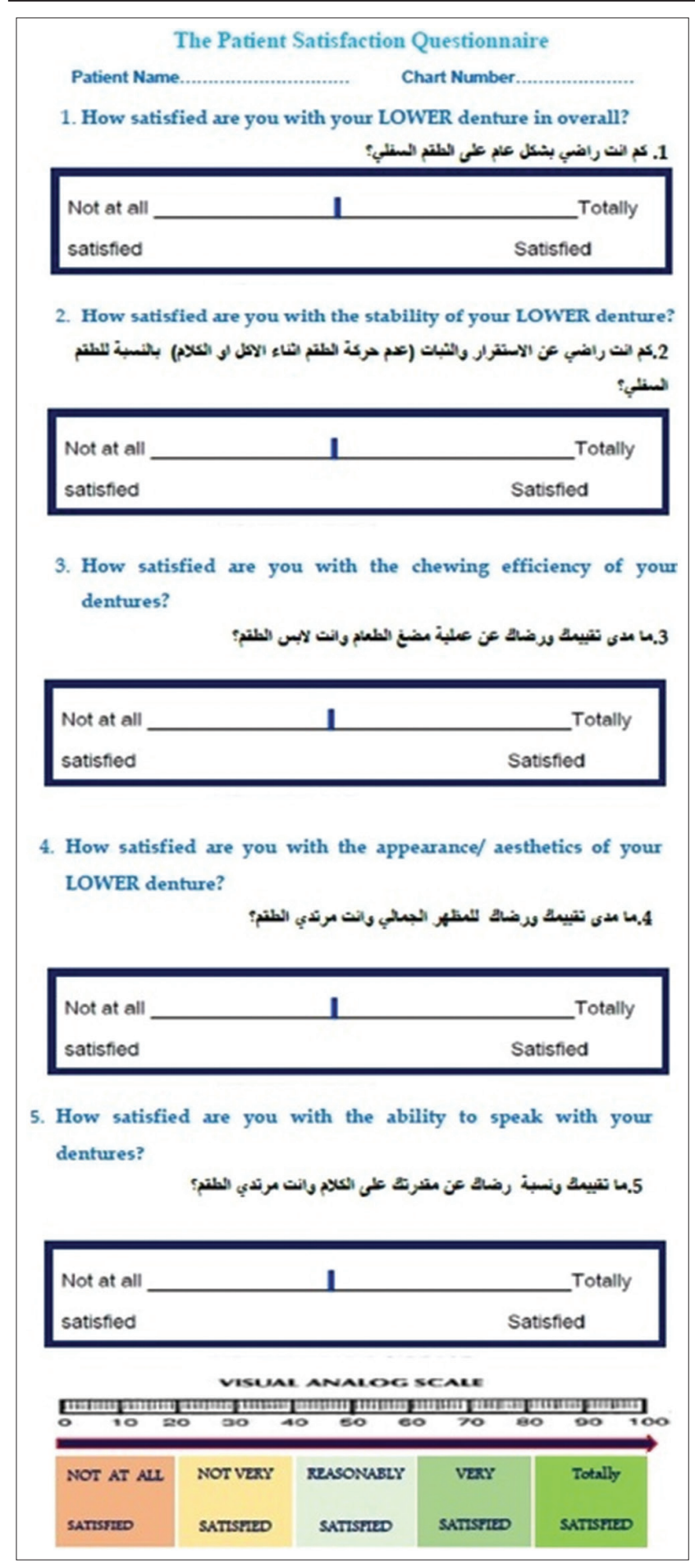

Figure 7: Patient satisfaction questionnaire

\section{Secondary outcome: Bone height change ( $\mathrm{mm}$ )}

Standardized intraoral radiographs were taken using the long cone parallel technique at baseline. The standardization process was done by employing a positioner ${ }^{18}$, to which the film ${ }^{19}$ was attached to be parallel to the long axis of the implant and perpendicular to the

18 X-ray Holders, New IDA Dabi Atlante Brazil

19 PSP Plates Soredex DIGORA® - Size 2) KAVO Imaging Brazil
X-ray central cone. A silicone bite registration material ${ }^{20}$ splinted with chemical cured acrylic resin ${ }^{21}$ was attached to the positioner and the patient was instructed to bite on it to construct a jig that had a print of the occlusal surfaces of the patient's teeth on. Thus, by that jig the patient would be instructed to position the positioner in the same fixed position for each time an X-ray would be taken. Accordingly, a standard radiograph would be taken. Afterward, the imaged peri-apical film was scanned using DIGORA $\AA^{22}$ scanner to digitize the image and saved on the personal laptop of the principal investigator with the date of the imaging procedure. For each patient a customized jig was constructed and saved for the follow-up visits. The digital images were marked with their time points and saved in each patient file

For assessing the bone height changes;

- The digital radiographs were uploaded to Soredex DIGORA Optime Classic software.

- For each implant or mini-implants two lines were identified through drawing a line from tool bar in the software, one line representing the implant platform, and the other representing the crestal bone in both mesial and distal sides of the implant.

- Then using the calibration tool, a calibrated ruler was drawn from the line of implant platform till the tip of the implant and calibrates the image through $10 \mathrm{~mm}$ (the length of the implant).

- $\quad$ Using the measuring tool; the distance was measured between the two lines (implant platform and crestal bone) from the mesial and distal surface for each implant, and saved in the patient's file.

- These measurements were repeated at baseline (T0), 6 months (T1) and 12 months (T2) for each patient (Figure 8).

- $\quad$ The values of (T1-T0), (T2-T1), and (T2-T0) were then calculated.

\section{Statistical analysis}

Statistical analysis was performed with SPSS $20^{\circledR 23}$, Graph Pad Prism ${ }^{\circledR 24}$, and Microsoft Excel $2016^{25}$. Data were presented as means and standard deviation (SD) values.

Independent $\mathrm{t}$ test was performed between both groups at each fixed time interval for both patient satisfaction using (VAS) and bone height changes

The results of this study were represented in tables and graphs. The significant level was set at $\mathrm{P} \leq 0.05$.

\footnotetext{
20 Futar®| Putty/Regular Set, Kettenbach Germany

21 Peka tray Acrostone, England

22 SOREDEX ${ }^{\mathrm{TM}}$ DIGORA ${ }^{\mathrm{TM}}$ Optime, KaVo Dental, USA

23 Statistical Package for Social Science, IBM, USA.

24 Graph Pad Technologies, USA.

25 Microsoft Co-operation, USA.
} 


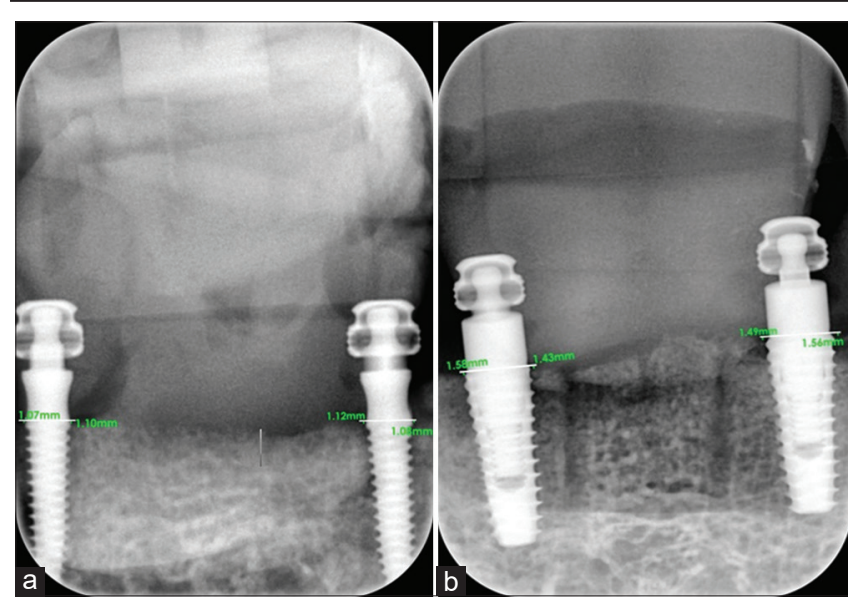

Figure 8: Intraoral radiograph for (a) intervention group (b) comparator group

\section{Results}

\section{Primary outcome}

\section{Evaluation of patient satisfaction}

The mean \pm SD of overall satisfaction was higher in the treatment than the control group with statistically significant difference $[\mathrm{t}(18)=6.2, \mathrm{p}=0.00]$ at baseline, $6[\mathrm{t}(18)=5.2, \mathrm{p}=0.00]$ and 12 months [t(18) $=4.04, p=0.00]$ follow-up (Figures 9-13). Other measured parameters such as denture stability, ability to speech using the denture, esthetics and chewing efficiency were higher in the treatment than control group with no statistically significant difference at baseline, 6 and 12 months follow-up listed in Table 1.

\section{Secondary outcome}

\section{Evaluation of bone height changes}

Statistically significance difference was found between treatment and control groups in mesial and distal surfaces and in the overall value of bone changes between 6 months and base line (T1-T0), between 6 and 12 months (T2-T1) and between 12 months and base line (T2-T0) as shown in Table 2 and Figure 14.

\section{Discussion}

Edentulous patients with compromised alveolar ridge usually suffered from lack of retention and stability during conventional denture wear. For that using osteo-integrated implants underneath the denture offered a better solution, especially in mandibular ridge. Thus using implant-retained overdenture was considered a valid and effective treatment option [9]. As consequences, implant improved stability, retention, chewing efficiency and overall patient satisfaction [10]. Multiple factors such as bone width, quality, systematic condition of the patient, and patient's acceptance of surgery can affect the implant's type to be used. For instance, conventional implants offered considerable retention and stability but required specific bone width. Accordingly, they could not be placed in thin alveolar unless ridge management was considered. Another possible option is mini-implant. They have the advantage of instantly inserted using flapless approach without the need for ridge management.

Only patients with Angle's Class I skeletal relationship were included in the study. Patients with Angle's Class II and III skeletal relationship had different applied forces on the dentures than Class I patients. Modifications in setting of the teeth would be required to neutralize these applied forces, thus they cannot follow the standard method of denture teeth setting [11].

The patients were selected to have inter-arch distance $\geq 12 \mathrm{~mm}$, to have sufficient space for the male and female parts of the attachments, denture base, and teeth placement. In addition this space was needed to adopt adequate closest speaking space, and to fulfill the esthetics requirements [12].

Patients having temporomandibular disorders were excluded because this might affect the direction of the applied force on the dentures; moreover, temporomandibular disorders would affect the results of patient's satisfaction as TMDs' symptoms would mask the improvement expected from the overdentures.

Patients present with severe systemic diseases as uncontrolled diabetes, bleeding disorders, neuromuscular disorders, psychiatric disorders, and patients on chemotherapy or radiotherapy were excluded as they would require special management in their drug doses, short appointment visits which were early morning. Furthermore, they would be more liable to drop out during the follow-up period of the trial [13].

Heavy smoker patients would burden the physical retention of complete dentures which mainly relay on surface tension and the thin film of saliva between the denture and the tissues for capillary attraction [11]. It was claimed that smoking decreases the salivary flow rate causing xerostomia which

Table 1: Comparison between patient satisfaction in both groups at different time points (Independent t-test)

\begin{tabular}{|c|c|c|c|c|c|c|c|c|c|c|c|c|c|}
\hline \multicolumn{2}{|c|}{ VAS score at baseline } & \multirow[t]{2}{*}{$\mathrm{t}$} & \multirow[t]{2}{*}{ df } & \multirow[t]{2}{*}{$p$-value } & \multicolumn{2}{|c|}{ VAS score at 6 months } & \multirow[t]{2}{*}{$\mathrm{t}$} & \multirow[t]{2}{*}{ df } & \multirow[t]{2}{*}{$p$-value } & \multicolumn{2}{|c|}{ VAS score At 12 months } & \multirow[t]{2}{*}{$\mathrm{t}$} & \multirow[t]{2}{*}{$\overline{d f}$} \\
\hline Group I M \pm SD & Group II $\mathrm{M} \pm \mathrm{SD}$ & & & & Group I M \pm SD & Group II $\mathrm{M} \pm \mathrm{SD}$ & & & & Group I M \pm SD & Group II M \pm SD & & \\
\hline $82.2 \pm 5.74$ & $69.0 \pm 3.51$ & 6.20 & 18 & $0.00^{*}$ & $85.4 \pm 4.79$ & $75.3 \pm 3.84$ & 5.20 & 18 & $0.00^{*}$ & $86.1 \pm 5.03$ & $76.3 \pm 5.77$ & 4.04 & 18 \\
\hline $81.3 \pm 6.355$ & $80.3 \pm 4.73$ & 0.39 & 18 & 0.60 & $84.9 \pm 4.78$ & $82.1 \pm 5.27$ & 1.24 & 18 & 0.10 & $85.7 \pm 2.37$ & $83.7 \pm 4.73$ & 1.19 & 18 \\
\hline $80.9 \pm 3.77$ & $79.8 \pm 6.11$ & 0.48 & 18 & 0.50 & $83.6 \pm 4.22$ & $82.2 \pm 6.11$ & 0.59 & 18 & 0.43 & $85.8 \pm 4.29$ & $84.8 \pm 4.09$ & 0.53 & 18 \\
\hline $78.7 \pm 1.22$ & $78.3 \pm 2.93$ & 0.48 & 18 & 0.63 & $82.2 \pm 3.86$ & $80.3 \pm 4.81$ & 0.97 & 18 & 0.21 & $79.1 \pm 3.02$ & $77.8 \pm 3.19$ & 0.93 & $1 \varepsilon$ \\
\hline $79.9 \pm 3.16$ & $78.2 \pm 4.28$ & 1.00 & 18 & 0.11 & $80.6 \pm 2.97$ & $79.1 \pm 3.95$ & 0.95 & 18 & 0.20 & $81.8 \pm 2.63$ & $80.7 \pm 2.88$ & 0.89 & 18 \\
\hline
\end{tabular}


Table 2: Comparison in bone height changes between Group I and II at different time points (Independent t-test)

\begin{tabular}{|c|c|c|c|c|c|c|c|c|c|c|c|c|c|c|c|}
\hline \multirow[t]{2}{*}{ Parameters } & \multicolumn{2}{|c|}{ At base line $M \pm S D$} & \multirow[t]{2}{*}{$\mathrm{T}$} & \multirow[t]{2}{*}{ df } & \multirow[t]{2}{*}{$\mathrm{p}$-value } & \multicolumn{2}{|c|}{ After 6 months $\mathrm{M} \pm \mathrm{SD}$} & \multirow[t]{2}{*}{$\mathrm{t}$} & \multirow[t]{2}{*}{ df } & \multirow[t]{2}{*}{$\mathrm{p}$-value } & \multicolumn{2}{|c|}{ After 12 months $\mathrm{M} \pm \mathrm{SD}$} & \multirow[t]{2}{*}{$t$} & \multirow[t]{2}{*}{ df } & \multirow[t]{2}{*}{$\mathrm{p}$-value } \\
\hline & Group I & Group II & & & & Group I & Group II & & & & Group I & Group II & & & \\
\hline Mesial & $0.1 \pm 0.06$ & $0.8 \pm 0.071$ & 22.83 & 18 & $0.00^{*}$ & $0.31 \pm 0.09$ & $1.2 \pm 0.10$ & 20.91 & 18 & $0.00^{*}$ & $0.96 \pm 0.04$ & $1.9 \pm 0.05$ & 42.02 & 18 & $0.00^{*}$ \\
\hline Distal & $0.15 \pm 0.07$ & $0.9 \pm 0.08$ & 22.31 & 18 & $0.00^{*}$ & $0.35 \pm 0.06$ & $1.3 \pm 0.07$ & 30.34 & 18 & $0.00^{*}$ & $1.05 \pm 0.09$ & $2.1 \pm 0.09$ & 25.10 & 18 & $0.00^{*}$ \\
\hline Overall & $0.25 \pm 0.03$ & $1.7 \pm 0.023$ & 116.35 & 18 & $0.00^{*}$ & $0.66 \pm 0.04$ & $2.5 \pm 0.04$ & 94.52 & 18 & $0.00^{*}$ & $2.01 \pm 0.04$ & $4.00 \pm 0.04$ & 103.37 & 18 & $0.00^{*}$ \\
\hline
\end{tabular}

accordingly would jeopardize physical retention of complete denture. Furthermore, smoking may affect the long term success of the implants' osteointegration process, it was reported that increase the number of cigarettes (more than one pack per day) would increase the implant failure [14].

Before implant placement, the patient denture was duplicated to construct radiographic and surgical stent. That was done to ensure ideal implant placement, thus the forces applied on the implants and the prosthetic components exhibited favorable force direction. In addition, implant placement was guided by a prosthetically driven position [15].

All the surgical procedures were done under complete aseptic conditions to avoid infection during and after implant placement. Pre-surgical antibiotics and chlorhexidine were administered to the patients to decrease the bacterial load and the risk of infection during the healing period after surgical procedures. It was stated that pre-operative antibiotics administration reduced implant failure [16].

To control the temperature during the process of drilling and avoid bone necrosis, specific precautions were considered. The drilling was performed using sharp drills with gradual increase in diameter at low speed in intermittent pattern, in addition to continuous copious irrigation throughout the procedure with cool sterile saline solution [17].

The site of the conventional implants and the mini-implants was chosen to be in the canine/ lateral region interforaminal to decrease the risk of the mandibular deflection and mandibular torsion [18]. Moreover, placing the implants more distally would be interfered with the inferior alveolar canal. However, placing the implants in the symphyseal region would benefit from the quality of the compact bone interforaminal which in turns ensure successful implants for long periods as was stated by Bergendal and Engquist [19].

In the present study, two implants were chosen for supporting overdenture for both groups based on the findings of 5-years follow-up study [20]. No significant differences were reported between 2- and 4-implantsupported mandibular overdentures in terms of peri-implant parameters, prosthetic parameters, clinical performance, and radiologic changes. Further statement by Thomason et al. [21] was that two-implant overdenture was the minimum standard that should be sufficient in terms of stability, retention and clinical performance for most people, taking into consideration performance, patient satisfaction, cost, and clinical time. In addition, Kurşun and Akan [22] in a recent study reported that 2- and 4- supported mandibular overdentures exhibit equal amount of bone changes after 1 year of performance. Thus, using 2 implants would be recommended in terms of lowering the cost, post-operative pain, and number of surgical procedures.

It was the same for the mini-implant as reported by De Sauza et al. [8], 2 mini-implant supported overdentures had intermediate patient satisfaction in terms of chewing, speech, esthetics, retention, and stability. Furthermore Ribeiro et al. [23] reported that using 2 mini-implant supported overdenture provoked less pain in the initial healing period and offer less difficulty in maintain oral hygiene than 4 mini-implant supported overdentures.

For the intervention group, the mini-implants were chosen with diameter $2.5 \mathrm{~mm}$ and $10 \mathrm{~mm}$ length to be inserted in the narrow ridges with sufficient bone margin, thus ensured more stability and success rate, as mini-implants were stated to have high survival rate and success rate in addition to adequate clinical behavior as retainers for over-denture [24].

While in the comparator group, the conventional implants used were threaded, self-tapping, root form implants, $10 \mathrm{~mm}$ length, and $3.6 \mathrm{~mm}$ width. This implant design was used to provide primary stability during the initial healing period. In addition, the implant design had adequate contact area between the implant with surrounding bone for better osseointegration as was recommended by [25]. In the present study, the alveolar ridges were narrow and indicated for expansion, the maximum implant diameter with less complication was selected according to recommendation of Elsyad et al. [26] to decrease the amount of strain in the implants supported overdenture.

Full thickness flap was performed in the comparator group to allow the split expansion later, not only for implant insertion. Single crestal and two vertical osteotomies were performed to avoid cracking of high density bone during the expansion of the thin alveolar ridge, in addition to provide better visibility. The need of two vertical osteotomies for alveolar expansion necessitated the use of full thickness flap and that was in agreement with the technique adopted by Ribeiro et al. [23] Although it was reported by Jensen et al. [27] that the amount of bone resorption subsequent to partial flap thickness $(2 \mathrm{~mm}$ ) was quite less than following the full flap thickness $(3.9 \mathrm{~mm})$, the survival rate of the implants after full thickness flap for expansion was higher than of those partial thickness. On the other hand, full thickness flap was performed in the intervention group, to allow 
alveolar ridge plateauing, in addition decreasing the confounders between the two groups.

Alveolar ridge plateauing was performed, in the comparator group before ridge splitting in accordance to Ribeiro et al. [23]. That procedure was performed to flatten the alveolar ridge thus the splitting procedure would be safe and stable to decrease the risk of drill slipping and soft tissue injury. On the other hand, plateauing was performed before mini-implant insertion in the intervention group to allow the locator drill to be stable without slippage.

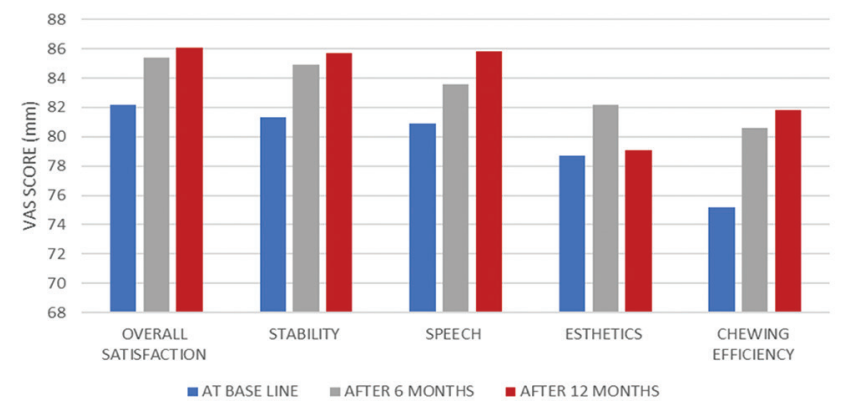

Figure 9: Bar chart representing patient satisfaction in the miniimplant group

Regarding the comparator group, the alveolar ridge expansion was performed using engine-driven expanders in sequential manner in the site of implant insertion. Engine-driven expanders are non-cutting drills that could enhance width expansion of thin alveolar ridges without using a surgical mallet; they can also be used as condensers of trabecular bone. About $100 \%$ success rate of the implant placed after using engine-driven expanders was reported in a recent systematic review by Jha et al. [28] In addition, it was reported that engine driven expanders utilized less chair time which in turns minimized surgical trauma and prevents bone heating. It was reported that engine-driven expanders resulted in more alveolar bone width with less bone trauma, patient discomfort during the procedures and post-operative pain in relation to conventional instruments like mallets and osteotomes.

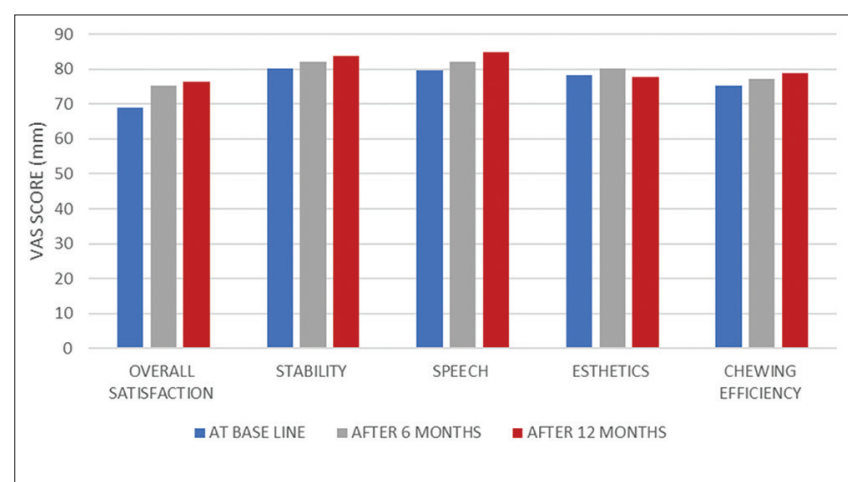

Figure 10: Bar chart representing patient satisfaction in the conventional implant group

In the present study, the space created by the expansion was not filled with bone grafting material, in contrast to Anitua et al. [29] that was attributed to the small size of the created gap that was less than $3 \mathrm{~mm}$. Thus, as recommended by Jensen et al. [27] bone grafting procedures was not performed.

In terms of loading time, both conventional implants and mini-implants in the groups were loaded 3 months after the implant insertion. That resulted in decrease the risk of overloading and chance of early implant failure. This was in agreement of Kern et al. [30] that recommended that delayed loading of implants offered superior survival rate if compared with implants immediately loaded with mandibular overdenture.

During the 3 months healing period after implant placement and before overdenture delivery, the conventional complete denture was used. The denture was relined after implant placement. In addition, in the follow-up visits periodic relining with soft liner was performed to prevent any undue loading forces to implants that can jeopardize the osseointegration process. Furthermore, soft liner acted as shock absorber which greatly increases patient comfort [31].

Ball attachment was used in the study as overdenture anchors. This was because it was reported by Gotfredsen and Holm [32] that ball attachment overdenture had $100 \%$ survival rate in 5 year follow-up period, further the ball attachment required less repairs and exhibited less complications if compared to bar attachment. On the other hand, ball attachment required less post-insertion aftercare and activation of retention in relation to locator attachment as reported by Krennmair et al. [33]

To quantify patient satisfaction, patients received visual analog scale (VAS) graded from 0 to 100 , as 0 was not satisfied and 100 was highly satisfied. Using that graded scale allowed patients to rate their perception in percentage not just answering yes/no that scale was considered highly expressive to quantify the patient discomfort rather than answering with extreme answers only. In addition, VAS was reported to be valid an reliable method for evaluating patient satisfaction as reported by previous studies [34], [35].

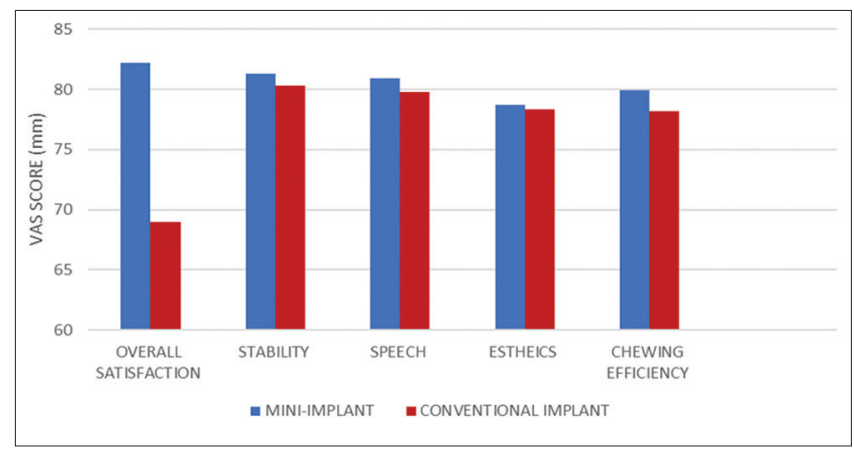

Figure 11: Bar chart representing the comparison in patient satisfaction between both groups at baseline

For evaluation of marginal bone changes, the long cone paralleling technique and a film holder with customized jig was used. This technique was adopted for standardize the radiographs taken for each 
patient at different points of time (baseline, 6 months and 12 months). Thus, the comparison between the measurements would be free of any radiographic errors, decreasing the confounders and made the results accurate and true. This was in agreement with Daros et al. [36] that stated the validity and accuracy of using this technique in quantifying the bone height changes.

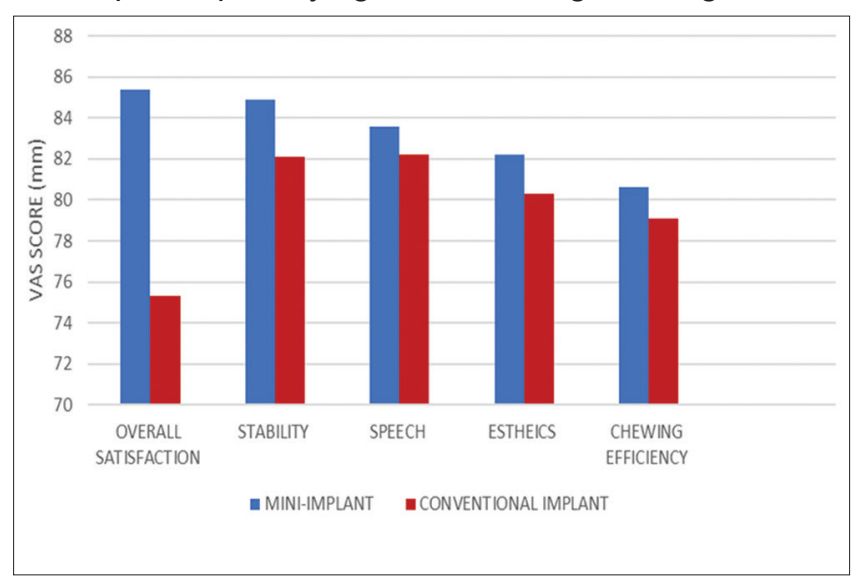

Figure 12: Bar chart representing the comparison in patient satisfaction between both groups after 6 months

The radiograph to evaluate the bone changes was taken using Digora $尺$ (the photo stimulus phosphor digital radiographic system, USA). Using photo stimulus phosphor digital plates (PSP) rather than conventional radiograph gave more accurate results and more fine details in terms of the bone level around the implants. However, PSP plate had some difficulties in placement and overlapping due to its flexibility which was eliminated using the film holder and customized jig [37].

In our results, patients were reasonably satisfied to totally satisfied after receiving the overdentures in both groups in agreement to the previous studies who reported that treatment using overdentures improved patient satisfaction [8], [23].

At base line; overall satisfaction was statistically significant in the mini-implant group in comparison to the conventional implant group in agreement with the results De souza et al. [8]. This might be attributed to the previous surgical procedures that were executed for comparator group for the alveolar ridge splitting and expansion. On the contrary, the procedure of the mini-implant insertion was relatively simpler and less traumatic for the patients.

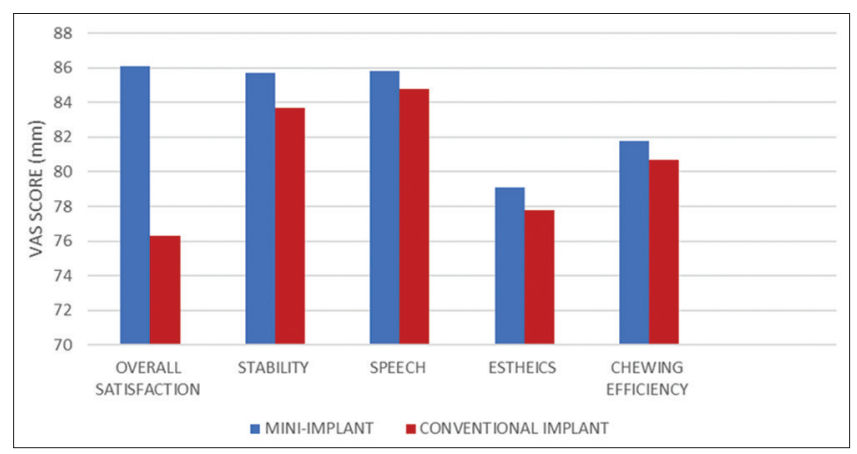

Figure 13: Bar chart representing the comparison in patient satisfaction between both groups after 12 months
The VAS score of the overall satisfaction in both groups relatively increased after the first 6 months of treatment, this could be attributed to the improvement of the quality of life as a result of overdenture treatment rather than conventional dentures as reported by many previous studies [8], [38], [39], [40], [41].

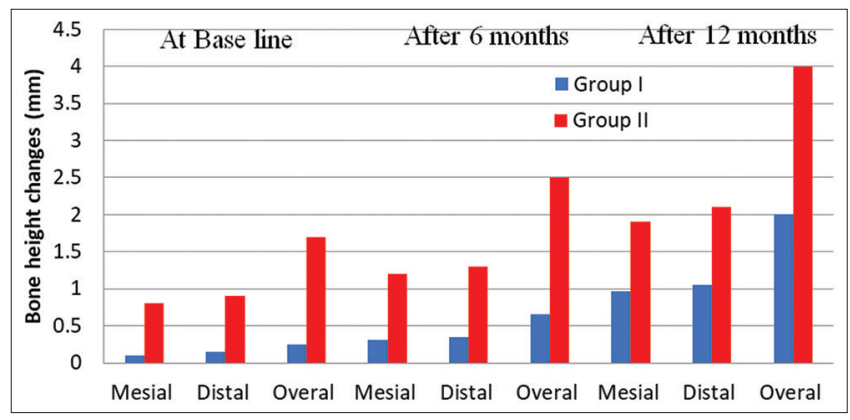

Figure 14: Bar chart representing the difference in bone height changes at different time points

On the other hand, the difference in the overall satisfaction in both groups from 6 months to 12 months follow-up was quite less than the first 6 months. That could be explained as the patients getting used to the overdentures in the second 6 months, thus the difference in the performance and the satisfaction was not that much as reported by De souza et al. [8]

After 6 and 12 months follow-up period, there was no statistical significant difference between the mini-implant and conventional group in the stability, speech, esthetics, and chewing efficiency, which was consistent with the results of De Souza et al. [8] that was attributed to using the same ball attachment system and standardization of overdenture pick up procedures in both groups.

For the secondary outcome, at baseline there was statistically significant difference between the bone height change between the conventional implant group and mini-implant group favoring the mini-implant. The cause behind increased bone resorption in the conventional implant group might be the added surgical procedures of alveolar ridge splitting that initiated more bone resorption if compared to the flap reflection only in the mini-implant group, in addition to the second stage surgery that was performed in the conventional implants.

Similarly, at 6 and 12 months, the bone height changes were higher in the conventional implants than the mini-implants. The possible reason might be that the initial bone change at the base line in the conventional was higher than the intervention. In addition, the difference in the quality of bone surrounding the conventional implant group was less than the one around the mini-implant, because it was newly formed after the expansion procedure.

For the mini-implant group, after and 12 months follow-up the amount of bone resorption was less than that reported by El-sayad et al. [42] and Zygogiannis et al., [9] that might be due to the difference in the 
loading protocol. In our study, conventional loading was adopted while immediate loading was adopted by the other studies [42].

On the other hand, our reported results in the mini-implant was relatively higher than the data reported by Scepanovic et al. [43]; however, it was still within the accepted limit reported by Albrektsson et al. [44] The possible cause for that difference was the number of mini-implants supporting the overdenture, that study used 4 mini-implants while in our study we used only two mini-implants.

For the conventional implants, the amount of bone resorption was relatively higher than recorded by El-sayad et al., [26] which might be attributed to the surgical procedures of the ridge splitting and expansion which provoked more bone resorption.

\section{Limitations}

The ridge expansion procedures were traumatic for the patients with subsequent post-operative swelling which might have some effect on their VAS score in that technique. In addition, utilizing disks in splitting might increase the possibility of cortical bone fracture in some cases with very thin ridges, other less invasive methods for expansion might be take into account. Grafting material after expansion might be advised to decrease the amount of bone resorption. Finally, the follow-up period for 12 months could be considered short-term success, thus longer follow-up period to be considered for long-term bone height changes in both techniques.

\section{Conclusion}

\section{Within the limitations of this study, it was concluded that}

Overdenture supported by 2 mini-implants is a successful treatment option with high patient satisfaction, improved overall function and decrease bone height changes over twelve months of follow-up period in comparison to conventional implants.

\section{Recommendations}

Further studies are required with longer follow-up period to monitor the effect of both treatment modalities on the supporting structures and on the overall patient satisfaction.

\section{References}

1. Goodacre CJ. Implant overdentures: Their benefits for patients. Saudi J Med Med Sci. 2018;6(1):25-9. http://doi.org/10.4103/ sjmms.sjmms_136_17

PMid:30787807

2. Thomason JM, Lund JP, Chehade A, Feine JS. Patient satisfaction with mandibular implant overdentures and conventional dentures 6 months after delivery. J Prosthet Dent. 2004;91(2):197.

3. Ahn MR, An KM, Choi JH, Sohn DS. Immediate loading with mini dental implants in the fully edentulous mandible. Implant Dent. 2004;13(4):367-72. http://doi.org/10.1097/01. id.0000148560.65514.3d

PMid:15591999

4. Vi S, Pham D, Yian Y, Du M, Arora H. Mini-implant-retained overdentures for the rehabilitation of completely edentulous maxillae: A systematic review and meta-analysis. Int $J$ Enviroment Res Public Health. 2021;18(8):4377-92. http://doi. org/10.3390/ijerph18084377

PMid:33924167

5. Scarano A, Murmura G, Carinci F, Lauritano D. Immediately loaded small-diameter dental implants: Evaluation of retention, stability and comfort for the edentulous patient. Eur J Inflamm. 2012;10(1):19-23.

6. Bassetti MA, Bassetti RG, Bosshardt DD. The alveolar ridge splitting/expansion technique: A systematic review. Clin Oral Implants Res. 2016;27:310-24. http://doi.org/10.1111/clr.12537 PMid:25586966

7. Mohammed S, Hamed H. Comparative study between conventional denture and bone expansion over denture in treatment of thin ridge. Egypt Dent J. 2012;2-8.

8. de Souza RF, Ribeiro AB, Vecchia MP, Costa L, Cunha TR, Reis AC, et al. Mini vs. standard implants for mandibular overdentures. J Dent Res. 2015;94(10):1376-84. http://doi. org/10.1177/0022034515601959

PMid:26294416

9. Zygogiannis K, Aartman I, Parsa A, Tahmaseb A, Wismeijer D. Implant mandibular overdentures retained by immediately loaded implants: A 1-year randomized trial comparing the clinical and radiographic outcomes between mini dental implants and standard-sized implants. Int J Oral Maxillofac Implants. 2017;32(6):1377-88. http://doi.org/10.11607/jomi.5981 PMid:29140382

10. Park JB. Ridge expansion with acellular dermal matrix and deproteinized bovine bone: A case report. Implant Dent. 2007;16(3):246-51. http://doi.org/10.1097/ ID.0b013e3181237926 PMid: 17846540

11. Misch CE. Dental Implant Prosthetics. St Louis, Missouri: Mosby Co.; 2005.

12. Singh S, Gupta A, Efros AA. Unsupervised discovery of midlevel discriminative patches. Lecture Notes in Computer Science, 7573 LNCS(PART 2); 2012. p. 73-86.

13. Pizolato R, Gavião M, Berretin-Felix G. Maximal bite force in young adults with temporomandibular disorders and bruxism. Braz Oral Res. 2007;21(3):278-83. http://doi.org/10.1590/ s1806-83242007000300015

PMid:17710296

14. Naseri R, Yaghini J, Feizi A. Levels of smoking and denta implants failure: A systematic review and meta-analysis. 
J Clin Periodontol. 2020;47(4):518-28. http://doi.org/10.1111/ jcpe. 13257

PMid:31955453

15. Solow RA. Simplified radiographic-surgical template for placement of multiple, parallel implants. J Prosthet Dent. 2001;85(1):26-9. http://doi.org/10.1067/mpr.2001.112793 PMid:11174674

16. Esposito M, Grusovin MG, Maghaireh H, Worthington HV. Interventions for replacing missing teeth: Different times for loading dental implants. Cochrane Database Syst Rev. 2013;2013:CD003878

PMid:23543525

17. Lee $\mathrm{JH}$, Frias $\mathrm{V}$, Lee $\mathrm{KW}$, Wright RF. Effect of implant size and shape on implant success rates: A literature review. J Prosthet Dent. 2005;94(4):377-81. http://doi.org/10.1016/j. prosdent.2005.04.018

PMid:16198176

18. Miyamoto $\mathrm{Y}$, Fujisawa $\mathrm{K}$, Takechi M, Momota $\mathrm{Y}$, Yuasa $\mathrm{T}$ Tatehara S, et al. Effect of the additional installation of implants in the posterior region on the prognosis of treatment in the edentulous mandibular jaw. Clin Oral Implants Res. 2003;14(6):727-33. http://doi.org/10.1046/j.0905-7161.2003.00958.x PMid:15015949

19. Bergendal T, Engquist B. Implant-supported overdentures: A longitudinal prospective study. Int J Oral Maxillofac Implants. 1998;13(2):253-62.

PMid:9581412

20. Visser A, Raghoebar GM, Meijer HJ, Batenburg RH, Vissink A. Mandibular overdentures supported by two or four endosseous implants: A 5-year prospective study. Clin Oral Implants Res. 2005;16(1):19-25. http://doi. org/10.1111/j.1600-0501.2004.01085.x

PMid: 15642027

21. Thomason JM, Kelly SA, Bendkowski A, Ellis JS. Two implant retained overdentures a review of the literature supporting the McGill and York consensus statements. J Dent. 2012;40(1):2234. http://doi.org/10.1016/j.jdent.2011.08.017

\section{PMid:21911034}

22. Kurşun ÜB, Akan E. Radiographic determination of trabecular bone change in 2- and 4-implant-supported overdenture prostheses. Oral Surg Oral Med Oral Pathol Oral Radiol. 2021;131(3):364-70. http://doi.org/10.1016/j.00oo.2020.08.002 PMid:32859563

23. Ribeiro $A B$, Vecchia MP, Cunha TR, Sorgini DB, Dos Reis AC, Muglia VA, et al. Short-term post-operative pain and discomfort following insertion of mini-implants for retaining mandibular overdentures: A randomized controlled trial. J Oral Rehabil. 2015;42(8):605-14. http://doi.org/10.1111/joor.12287 PMid:25765784

24. Bielemann AM, Marcello-Machado RM, Del Bel Cury AA, Faot F. Systematic review of wound healing biomarkers in peri-implant crevicular fluid during osseointegration. Arch Oral Biol. 2018;89:107-28. http://doi.org/10.1016/j. archoralbio.2018.02.013

PMid:29510331

25. Lin CL, Wang JC, Ramp LC. Biomechanical response of implant systems placed in the maxillary posterior region under various conditions of angulation, bone density, and loading. Int J Oral Maxillofac Implants. 2008;23(1):57-64.

PMid: 18416413

26. Elsyad MA, Al-Mahdy YF, Fouad MM. Marginal bone loss adjacent to conventional and immediate loaded two implants supporting a ball-retained mandibular overdenture: A 3-year randomized clinical trial. Clin Oral Implants Res. 2011;23(4):496503. http://doi.org/10.1111/j.1600-0501.2011.02173.x

\section{PMid:21504479}

27. Jensen OT, Cullum DR, Baer D. Marginal bone stability using 3 different flap approaches for alveolar split expansion for dental implants a 1-year clinical study. J Oral Maxillofac Surg. 2009;67(9):1921-30. http://doi.org/10.1016/j.joms.2009.04.017 PMid:19686930

28. Jha N, Choi EH, Kaushik NK, Ryu JJ. Types of devices used in ridge split procedure for alveolar bone expansion: A systematic review. PLoS One. 2017;12(7):e0180342. PMid:28732054

29. Anitua E, Begona L, Orive G. Controlled ridge expansion using a two-stage split-crest technique with ultrasonic bone surgery. Implant Dent. 2012;21(3):163-70.

30. Kern M, Att W, Fritzer E, Kappel S, Luthardt RG, Mundt T, et al. Survival and complications of single dental implants in the edentulous mandible following immediate or delayed loading: A randomized controlled clinical trial. J Dent Res. 2018;97(2):163-70

31. Palla ES, Karaoglani E, Naka O, Anastassiadou V. Soft denture liners' effect on the masticatory function in patients wearing complete dentures: A systematic review. J Dent. 2015;43(12):1403-10. http://doi.org/10.1016/j.jdent.2015.09.005 PMid:26404406

32. Gotfredsen K, Holm B. Implant-supported mandibular overdentures retained with ball or bar attachments: A randomized prospective 5-year study. Int J Prosthodont. 2000;13(2):125-30. PMid: 11203620

33. Krennmair G, Seemann R, Fazekas A, Ewers R, Piehslinger E. Patient preference and satisfaction with implant-supported mandibular overdentures retained with ball or locator attachments: A crossover clinical trial. Int J Oral Maxillofac Implant 2012;27(6):1560-8.

PMid:23189311

34. MacEntee MI, Walton JN, Glick N. A clinical trial of patient satisfaction and prosthodontic needs with ball and bar attachments for implant-retained complete overdentures: Three-year results. J Prosthet Dent. 2005;93(1):28-37. http:// doi.org/10.1016/j.prosdent.2004.10.013 PMid:15623995

35. Cune M, Van Kampen F, van der BiltF B. Patient satisfaction and preference with magnet, bar-clip, and ball-socket retained mandibular implant overdentures: A cross-over clinical trial. Int J Prosthodont. 2005;18(5):99-105.

PMid:15889656

36. Darós P, Carneiro VC, Siqueira AP, De-Azevedo-Vaz SL. Diagnostic accuracy of 4 intraoral radiographic techniques for misfit detection at the implant abutment joint. J Prosthet Dent. 2018;120(1):57-64. http://doi.org/10.1016/j. prosdent.2017.08.008

PMid:29150129

37. Zhang W, Carolyn P, Huynh K, Inga-Lill K, Leon L. Comparison of technique errors of intraoral radiographs taken on film $\checkmark$ photostimulable phosphor (PSP) plates. Tex Dent J. 2012;129(6):586-96.

PMid:22866414

38. Emami E, Heydecke G, Rompré PH, de Grandmont $P$ Feine JS. Impact of implant support for mandibular dentures on satisfaction, oral and general health-related quality of life: A meta-analysis of randomized- controlled trials. Clin Oral Implants Res. 2009;20(6):533-44. http://doi. org/10.1111/j.1600-0501.2008.01693.x PMid: 19515032

39. Batisse C, Bonnet G, Bessadet M, Veyrune JL, Hennequin M, Peyron MA, et al. Stabilization of mandibular complete dentures by four mini implants: Impact on masticatory function. J Dent. 
2016;50:43-50. http://doi.org/10.1016/j.jdent.2016.04.012

PMid:27151558

40. Park JH, Lee JY, Shin SW. Treatment outcomes for mandibular mini-implant-retained overdentures: A systematic review. Int J Prosthodont. 2017;30(3):269-76. http://doi.org/10.11607/ ijp.4929

PMid:28319212

41. Kutkut A, Bertoli E, Frazer R, Pinto-sinai G, Fuentealba $R$ Studts J. A systematic review of studies comparing conventional complete denture and implant retained overdenture J Prosthodont Res. 2018;62(1):1-9. http://doi.org/10.1016/j. jpor.2017.06.004

PMid:28666845

42. Elsyad MA, Gebreel AA, Fouad MM, Elshoukouki AH. The clinical and radiographic outcome of immediately loaded mini implants supporting a mandibular overdenture. A 3-year prospective study. J Oral Rehabil. 2011;38(11):827-34. http:// doi.org/10.1111/j.1365-2842.2011.02213.x

PMid:21972846

43. Šćepanović M, Todorović A, Marković A, Patrnogić V, Miličić B, Moufti AM, et al. Immediately loaded mini dental implants as overdenture retainers: 1-Year cohort study of implant stability and peri-implant marginal bone level. Ann Anat. 2015;199:85-91. http://doi.org/10.1016/j.aanat.2013.12.005

PMid:24582754

44. Carlsson L, Röstlund $\mathrm{T}$, Albrektsson $\mathrm{B}$, Albrektsson $\mathrm{T}$, Brånemark $\mathrm{Pl}$. Osseointegration of titanium implants. Acta Orthop Scand. 1986;57(4):285-9. http://doi. org/10.3109/17453678608994393

PMid:3788488 